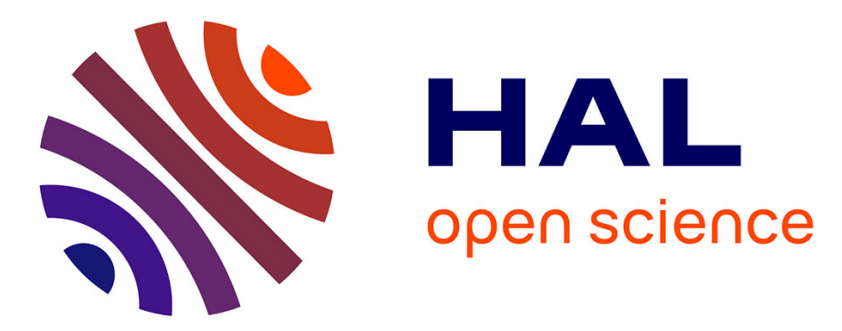

\title{
Multi-time scale analysis of sugarcane within-field variability: Improved crop diagnosis from satellite time series?
}

\author{
Agnes Begue, Pierre Todoroff, Johanna Pater
}

\section{- To cite this version:}

Agnes Begue, Pierre Todoroff, Johanna Pater. Multi-time scale analysis of sugarcane within-field variability: Improved crop diagnosis from satellite time series?. Precision Agriculture, 2008, 9 (3), pp.161-171. 10.1007/s11119-008-9063-3 . cirad-00664059

\section{HAL Id: cirad-00664059 http://hal.cirad.fr/cirad-00664059}

Submitted on 30 Jan 2012

HAL is a multi-disciplinary open access archive for the deposit and dissemination of scientific research documents, whether they are published or not. The documents may come from teaching and research institutions in France or abroad, or from public or private research centers.
L'archive ouverte pluridisciplinaire HAL, est destinée au dépôt et à la diffusion de documents scientifiques de niveau recherche, publiés ou non, émanant des établissements d'enseignement et de recherche français ou étrangers, des laboratoires publics ou privés. 


\section{MULTI-TIME SCALE ANALYSIS OF SUGARCANE WITHIN-FIELD}

\section{VARIABILITY: IMPROVED CROP DIAGNOSIS USING SATELLITE}

\section{TIME SERIES?}

Agnès BEGUE ${ }^{1}$, Pierre TODOROFF' ${ }^{2}$ Johanna PATER ${ }^{1}$

1. CIRAD, UMR TETIS, Montpellier, F-34093 France, email : agnes.begue@cirad.fr

2. CIRAD, UR SCA, Petit Bourg, Guadeloupe, F- 97170 France, email: pierre.todoroff@cirad.fr

\section{ABSTRACT}

Within-field spatial variability is related to multiple factors that can be time-independent or time-dependent. In this study, our working hypothesis is that a multi-time scale analysis of the dynamics of spatial patterns can help establish a diagnosis of crop condition. To test this hypothesis, we analyzed the within-field variability of a sugarcane crop at seasonal and annual time scales, and tried to link this variability to environmental (climate, topography, and soil depth) and cropping (harvest date) factors. The analysis was based on a sugarcane field vegetation index (NDVI) time series of fifteen SPOT images acquired in the French West Indies (Guadeloupe) in 2002 and 2003, and on an original classification method that enabled us to focus on crop spatial variability independently of crop growth stages.

We showed that at the seasonal scale, the within-field growth pattern depended on the phenological stage of the crop and on cropping operations. At the annual scale, NDVI maps revealed a stable pattern for the two consecutive years at peak vegetation, despite very different rainfall amounts, but with inverse NDVI values. This inversion is linked with the topography and consequently to the plant water status.

We conclude that (1) it is necessary to know the crop growing cycle to correctly interpret the spatial pattern, (2) single-date images may be insufficient for the diagnosis of crop condition or for prediction, and (3) the pattern of vigour occurrence within fields can help diagnose growth anomalies. 


\section{INTRODUCTION}

Image-based remote sensing can provide spatially and temporally distributed information for precision agriculture (Moran et al., 1997; Pinter et al., 2003). Aerial photographs and crop images, for instance, have been used to draw management zones as portions of a field that express homogeneous combinations of yield-limiting factors (e.g. Anderson and Yang, 1996). In order to optimize the inputs and the cropping schedule, however, it is also necessary to determine the causes of spatial variability in crop vigour.

Crop growth variability is related to multiple factors that can be time-independent or timedependent. The main time-independent factors of variability are linked to the substrate, like topography and soil type and depth, or to previous land use. Annual-linked factors may include anomalies in planting and emergence, or in weather conditions. Seasonal-linked factors may include plant diseases, weed development, severe climatic events or irrigation system mal-function. These time-independent and time-variable factors can also interact, leading to complex spatio-temporal patterns of crop vigour (Machado et al., 2002). Hyperspectral images, acquired in multiple and narrow spectral bands, can be used to detect crop nutrients and water stress conditions (Lelong et al., 1998). Unfortunately, most of the satellite or airborne sensors have a small number of broad spectral bands, and typically lack the diagnostic capability to identify a particular type of stress or to determine why biomass is at a certain level. According to Pinter et al. (2003), historic imagery, at field and farm levels, could be combined with agronomic and climatic data to map areas prone to water stress, nutrient deficiency, or pest problems under a particular environmental scenario.

Remote sensing studies using historic images are generally based on the premise that the spatial variability in crop yield is influenced by spatial variability in soil factors at a similar scale, and make use of image time series at an annual scale (e.g. Boydell and Mc Bratney, 
2002). However, the number of years of consecutive image data required to return an acceptably stable map differs depending on the study, from the recommended five years (Boydell and Mc Bratney, 2002) to a longer term database for crops under variable environmental conditions (Lamb et al., 1997; Schepers et al., 2004). At the seasonal scale, the dynamics of spectral vegetation indices are generally studied in order to determine the best period to delineate yield potential zones (Zarco-Tejada et al., 2005; Yang and Everitt, 2002), which is not sufficient to establish crop diagnosis.

In this study, since spatial variability is related to multiple factors that can be timeindependent or time-dependent, our working hypothesis is that a multi-time scale analysis of the dynamics of spatial patterns can help to establish diagnosis on crop conditions. To test this original hypothesis, we analyzed the within-field variability of sugarcane crop at two different time-scales, seasonal and annual, and tried to relate this variability to cropping (harvest date) and environmental (climate, topography and soil depth) factors. This analysis is based on a sugarcane field normalized difference vegetation index (NDVI) time series of fifteen SPOT images of the French West Indies (Guadeloupe) from 2002, 2003, and 2004 (SUCRETTE project; Ribbes et al., 2002).

\section{MATERIAL AND METHODS}

\section{Crop material and study site}

Sugarcane (Saccharum officinarum L.) is a semi-perennial grass with fibrous stalks two to six meters tall, belonging to the Graminae family. It is a vegetatively propagated crop, and the propagules are the stem cuttings. After 18-24 months from initial planting, the plant crop is harvested, and the buds on the leftover underground stubbles germinate again and give 
rise to another crop. This crop, called a ratoon crop, is harvested about every 12 months for up to four years or more, before being renewed due to decreasing yield.

The study site is a 8 ha field named Sahara located in Gardel Estate (169124" N; 6120'29" W), a planter-miller growing sugarcane in the French West Indies (Guadeloupe).

\section{Cropping data}

Sahara field was planted with C06415 cultivar in 2000, and harvested on June 10, 2002, April 30, 2003 (41.9 t) and June 9, 2004 (63.8 t) during the study period. During this period, the crop was rainfed and healthy.

\section{Environmental data acquisition and processing}

The climate station closest to Sahara field is Boisvin, less than $2 \mathrm{~km}$ away. The recorded rainfall was respectively $1185 \mathrm{~mm}$ and $1905 \mathrm{~mm}$ for the 2002-03 and 2003-04 growing seasons (from June to May); the average annual rainfall (1977-2000 period) on the Gardel area being $1325 \mathrm{~mm}$.

The Sahara field Digital Elevation Model (DEM) was extracted from the Guadeloupe DEM. The Guadeloupe DEM was produced in 2002 by $\mathrm{DDAF}^{1}$ from aerial orthophotos (ORTHO® DB, IGN) and ground control points. The DEM is in UTM $20 \mathrm{~N}$ projection, and with horizontal and vertical resolutions of $10 \mathrm{~m}$ and $1 \mathrm{~m}$ respective.

Soil depth over the reef limestone subsoil was measured on Sahara field in 2004 using the electric resistivity method (Hesse, 1966). Measurements of resistivity $r(\Omega m)$ were made at

\footnotetext{
${ }^{1}$ Direction Départementale de l'Agriculture et des Forêts
} 
the corners of a $20 \mathrm{~m}$ by $20 \mathrm{~m}$ grid, localized with a Trimble Pathfinder GPS, and converted into soil depths $z(m)$ with coefficients calibrated for the Gardel vertisols (Cabidoche, 1985) : $z=2-0.74 \ln (r-3)$

Soil depth values were then interpolated using kriging and rasterized at $10 \mathrm{~m}$ resolution to be compatible with the spatial resolution of SPOT images.

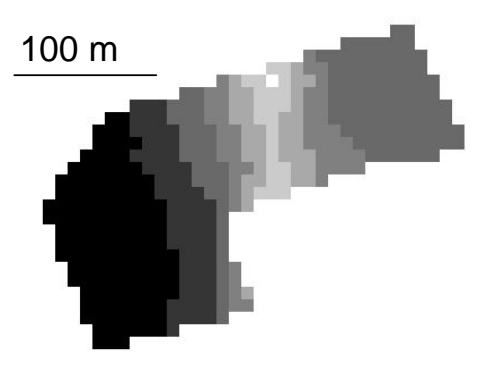

a) Digital Elevation Model

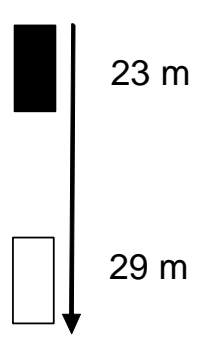

b) Soil depth

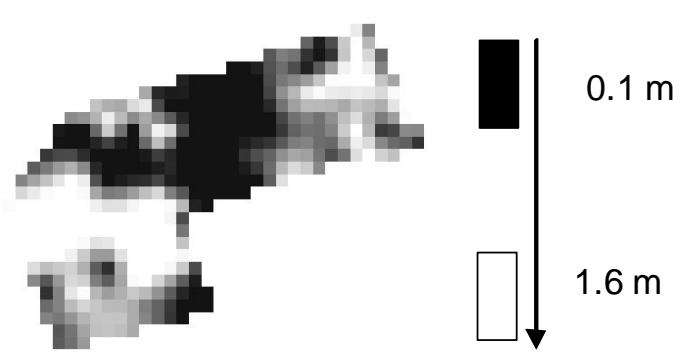

Figure 1: Environmental data maps of Sahara field: a) Digital Elevation Model (Source: DDAF, 2002), and b) soil depth (Source: Catsidonis 2004, personal communication).

\section{Satellite data acquisition and processing}

A time series of SPOT images were acquired in 2002, 2003, and 2004 over Guadeloupe as part of a research project (Ribbes et al., 2002). For this study, a set of fifteen cloud-free images (thirteen SPOT5 images and two SPOT4 images) were selected over Gardel Estate (Table 1). The images were acquired at $20 \mathrm{~m}$ and $10 \mathrm{~m}$ resolution respectively for SPOT4 and SPOT5 satellites (red and near infrared bands), in raw format (level 1a) with no geometric pre-processing. 
Table 1 : List of the SPOT images and characteristics used in the study

\begin{tabular}{|llrrrrr|}
\hline & Acquisition date & Satellite & Incidence & Solar Elevation & Solar Azimuth & Phase \\
& & & Angle $(9$ & Angle $(9)$ & Angle (9) \\
& & & & & & \\
\hline 1 & Septemsor) & Angle $^{1}(9)$ & 67.2 & 127.8 & 29.0 \\
2 & October 24, 2002 & SPOT5 & -6.8 & 52.1 & 143.3 & 31.7 \\
3 & January 21, 2003 & SPOT5 & -16.5 & 46.7 & 145.7 & 32.9 \\
4 & February 11, 2003 & SPOT5 & -23.5 & 50.1 & 138.5 & 24.5 \\
5 & March 29, 2003 & SPOT5 & 7.0 & 66.3 & 122.2 & 30.4 \\
6 & April 30,2003 & SPOT5 & -23.5 & 68.9 & 91.7 & 4.6 \\
7 & May 4, 2003 & SPOT5 & 22.1 & 74.7 & 90.1 & 37.1 \\
8 & May 25,2003 & SPOT5 & 14.6 & 73.4 & 71.5 & 30.0 \\
9 & July 17, 2003 & SPOT5 & -25.1 & 66.5 & 73.2 & 11.9 \\
10 & September 12, 2003 & SPOT5 & -17.6 & 66.3 & 117.3 & 8.0 \\
11 & January 4, 2004 & SPOT5 & -2.2 & 45.9 & 151.0 & 42.7 \\
12 & January 31, 2004 & SPOT4 & 13.4 & 50.2 & 146.9 & 49.7 \\
13 & March 1, 2004 & SPOT5 & 5.8 & 57.4 & 135.5 & 37.5 \\
14 & April 12, 2004 & SPOT5 & -10.5 & 67.9 & 107.4 & 11.7 \\
15 & June 19, 2004 & SPOT5 & -24.9 & 67.0 & 68.0 & 13.8 \\
\hline
\end{tabular}

1 : Negative values for Right viewing

\section{Image pre-processing}

SPOT images were ortho-rectified using the SPOT geometric model provided by ERDAS IMAGINETM software (UTM 20N). For the orthorectification, we used the DEM and thirty control points scattered over the whole island. The control points were extracted from aerial ortho-photos $\left(\mathrm{ORTHO}{ }^{\circledR} \mathrm{DB}, \mathrm{IGN}\right)$. The image registration error was less than $10 \mathrm{~m}$ (less than 1 SPOT5 pixel).

In order to get comparable physical values between the images, the digital counts were converted to Top of Atmosphere (TOA) reflectances, using the following equation: 


$$
\rho=\frac{D C \cdot \pi}{G \cdot \cos \left(\theta_{S}\right) \cdot E_{S}}
$$

where $\rho$ is the TOA (Top Of Atmosphere) reflectance, $D C$ is the digital count, $G$ is the sensor absolute calibration gain (provided in the metadata associated with the image), $\theta_{S}$ is the solar zenith angle and $E_{S}$ is the solar radiation in the appropriate wavelength. To minimize the radiometric residual effects due to varying irradiance conditions, we used a ratio-based vegetation index (Tucker, 1979). The most commonly used is the Normalized Difference Vegetation Index (NDVI; Rouse et al., 1974), calculated as:

$$
N D V I=\frac{\rho_{N I R}-\rho_{R E D}}{\rho_{N I R}-\rho_{R E D}}
$$

where $r_{\text {NIR }}$ and $r_{\text {RED }}$ are respectively the TOA reflectances in the near infrared and the red bands.

No atmospheric correction was performed since only clear sky images were selected and because the images were mainly processed (classification and correlation) on a daily basis.

\section{Field image classification}

To help visualize and summarize field spectral data for each date the field NDVI values were aggregated into five discrete categories. To do this, subset NDVI images corresponding to the boundaries of Sahara field (minus a buffer zone of $20 \mathrm{~m}$ ) were created from the time series. The aggregation was done according to the equal count (quintiles) or equal-area classification, where approximately the same number of observations ( $20 \%$ of the total) was put into each class. This technique allows focusing on crop spatial variability independent of the crop growth stages. 


\section{Correlation between variables}

To complement the visual and qualitative result obtained from the image classification, we used the Spearman coefficient to calculate the correlation between the NDVI images, and between NDVI values, elevation, and soil depth. The Spearman coefficient assesses how well an arbitrary monotonic function can describe the relationship between two variables, without making any assumptions about the frequency distribution of the variables or the linearity of the relationship.

\section{RESULTS}

\section{Environmental data}

The satellite time series covered two consecutive cycles of sugarcane growth with different rainfall amounts (Figure 2a). The 2002-2003 cycle showed a rainfall deficit of $140 \mathrm{~mm}$ compared to the 24-year rainfall average, with deficit records in November and December (respectively $112 \mathrm{~mm}$ and $87 \mathrm{~mm}$ ) at the end of the rainy season. In contrast, the rainfall of the 2003-2004 cycle showed a surplus of $580 \mathrm{~mm}$ compared to the 24-year average with peaks in November and December (respectively $116 \mathrm{~mm}$ and $327 \mathrm{~mm}$ ), due to particularly strong rainfall events. 

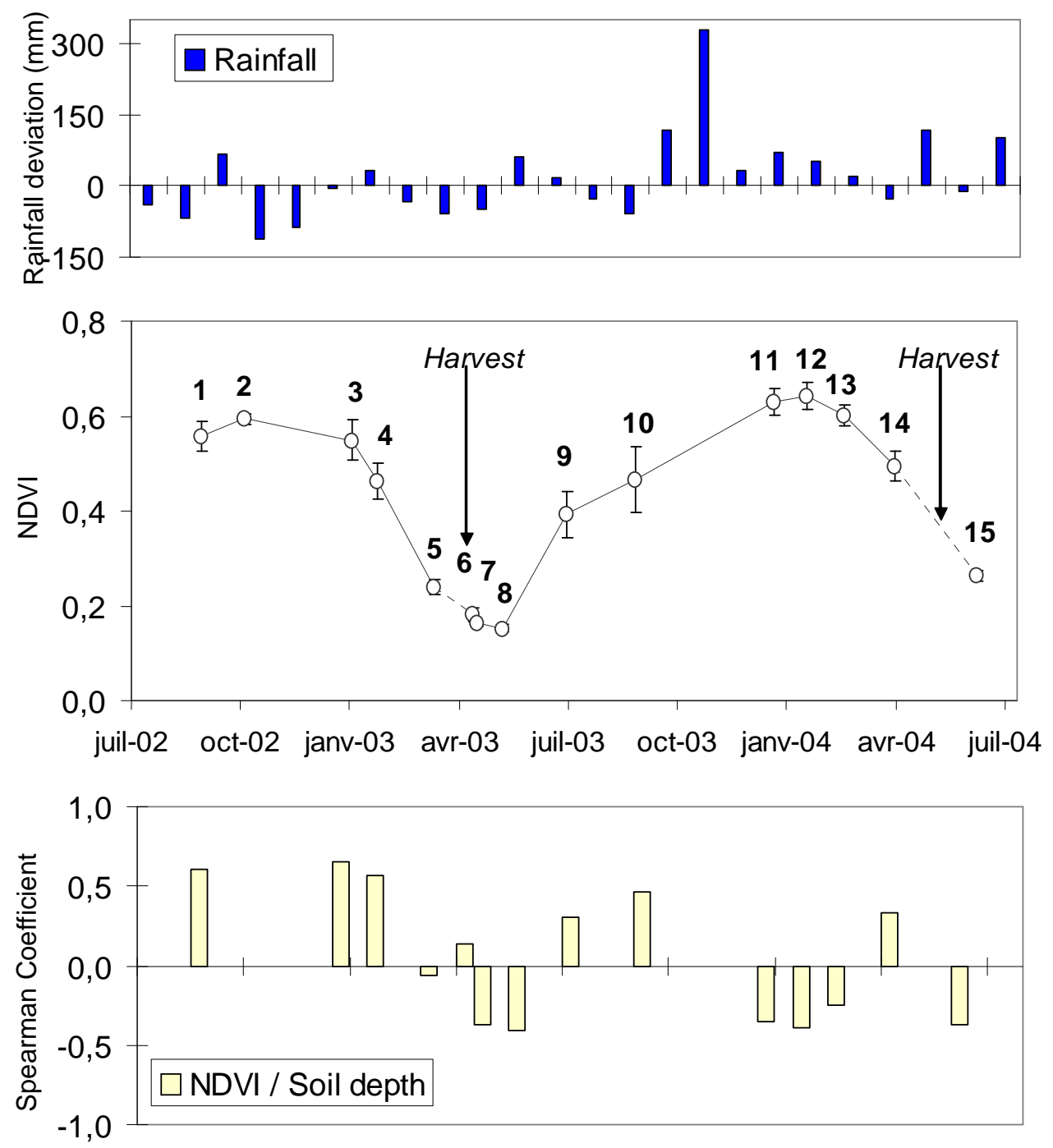

Figure 2 (a: top to $d$ : bottom): a) Boisvin monthly rainfall deviation from average over 24 years (1977-2000) at Gardel Estate, b) mean and standard deviation of Sahara field SPOT NDVI; Spearman coefficient between NDVI and soil depth (c) and elevation (d) at pixel scale.

\section{NDVI time series of sugarcane}

Figure $2 \mathrm{~b}$ shows the evolution of the mean NDVI of Sahara field throughout the two growing cycles. After harvest, in May and June 2003, when there are only crop residues present on 
the soil, the value of the NDVI is low, between 0.15 and 0.2 . The NDVI then increases rapidly as the vegetation re-grows and reaches its maximum at the end of the rainy season, with values between 0.7 and 0.8 , typical of a fully developed dense green canopy. When there is no water stress, as in 2003-2004 in Guadeloupe, the NDVI remains stable or decreases slowly during the maturation phase due to a slight decline in leaf chlorophyll and change in the canopy architecture (Almeida et al., 2006), and continues as such until harvest. In contrast, in cases of severe water stress as in 2002-2003 in Guadeloupe, the NDVI, after reaching its maximum, can decrease all the way down to 0.25 mainly due to the severe senescence of the leaves.

\section{Seasonal variations of NDVI patterns}

Within-field growth pattern depends on the phenological stage of the crop and the cropping operations. Figure 3 shows equal-population classes of Sahara field NDVI for each acquisition date during two consecutive growing cycles. During the growth stages (images 7, 8, and 15), the within-field spatial variability is high; at this stage, the vegetation cover is partial and the background is still visible. The within-field variability is linked to background variability factors such as the density and degradation status of cane residues, and to possible development of weeds. From the end of the growing stage to the initial maturation phase (images 1 to 4 , for the 2002-2003 season, and images 11 to 14 for the 2003-2004 season), the pattern of within-field variability stabilizes. This visual interpretation is confirmed by the high values of the correlation coefficients (from 0.63 to 0.83 ) obtained between images $1,3,4$ for the 2002-2003 season, and between images 11, 12, 13 for the 2003-2004 season (Table 2). At this stage, the crop is fully developed and the soil is no longer visible. On April 30, 2003 (image 6), the within-field variability map displays striped patterns, characteristic of the harvest in progress. 
However, in this time series, two images display unexpected growth patterns: the October 24, 2002 image (image 2) and the April 12, 2004 image (image 14). Although no particular conditions were noticed when they were acquired (Table 1), a heavy rainfall occurring two days before the October 24, 2002 image may have modified the crop architecture significantly enough to induce a change in the growth pattern observed in that image. For the April 2004 outlier, however, no reasonable explanation can be put forward at this point.

\begin{tabular}{|c|c|c|c|c|c|c|c|c|c|c|c|c|c|c|c|}
\hline $\begin{array}{c}\# \\
\text { image } \\
\end{array}$ & 1 & 2 & 3 & 4 & 5 & 6 & 7 & 8 & 9 & 10 & 11 & 12 & 13 & 14 & 15 \\
\hline 1 & 1.00 & & & & & & & & & & & & & & \\
\hline 2 & 0.25 & 1.00 & & & & & & & & & & & & & \\
\hline 3 & 0.71 & 0.08 & 1.00 & & & & & & & & & & & & \\
\hline 4 & 0.66 & 0.08 & 0.83 & 1.00 & & & & & & & & & & & \\
\hline 5 & -0.10 & -0.40 & 0.04 & 0.11 & 1.00 & & & & & & & & & & \\
\hline 6 & 0.14 & 0.04 & 0.09 & 0.12 & -0.12 & 1.00 & & & & & & & & & \\
\hline 7 & -0.31 & 0.01 & -0.28 & -0.23 & 0.05 & 0.01 & 1.00 & & & & & & & & \\
\hline 8 & -0.51 & -0.22 & -0.53 & -0.49 & 0.19 & -0.04 & 0.23 & 1.00 & & & & & & & \\
\hline 9 & 0.31 & 0.34 & 0.29 & 0.27 & -0.40 & 0.11 & -0.24 & -0.34 & 1.00 & & & & & & \\
\hline 10 & 0.52 & -0.25 & 0.64 & 0.53 & 0.17 & 0.00 & -0.35 & -0.35 & 0.10 & 1.00 & & & & & \\
\hline 11 & -0.45 & -0.19 & -0.43 & -0.45 & 0.17 & -0.36 & 0.18 & 0.35 & -0.09 & -0.13 & 1.00 & & & & \\
\hline 12 & -0.40 & -0.12 & -0.53 & -0.52 & -0.02 & -0.19 & 0.22 & 0.31 & -0.15 & -0.27 & 0.66 & 1.00 & & & \\
\hline 13 & -0.38 & -0.15 & -0.35 & -0.33 & 0.15 & -0.28 & 0.20 & 0.35 & -0.10 & -0.16 & 0.79 & 0.63 & 1.00 & & \\
\hline 14 & -0.01 & 0.02 & 0.14 & 0.08 & -0.09 & 0.04 & -0.13 & -0.08 & 0.27 & -0.13 & -0.11 & -0.16 & 0.03 & 1.00 & \\
\hline 15 & -0.46 & -0.14 & -0.52 & -0.48 & 0.00 & -0.02 & 0.18 & 0.41 & -0.21 & -0.40 & 0.32 & 0.45 & 0.32 & 0.00 & 1.00 \\
\hline
\end{tabular}

Table 2: Spearman correlation matrix calculated between the fifteen SPOT NDVI images of Sahara field. Values in bold are significantly different from 0 at $P<0.01$. 


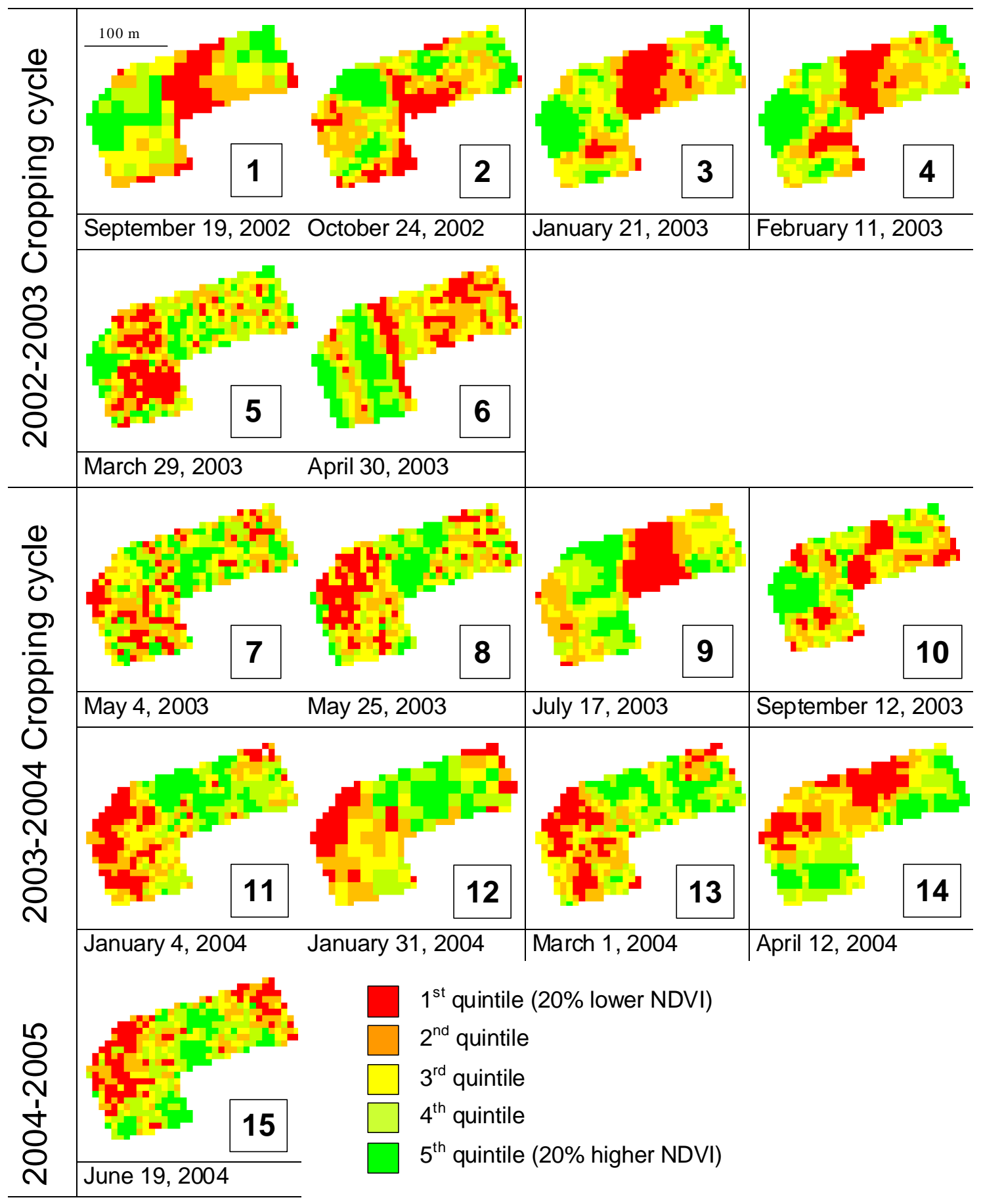

Figure 3: Sahara field images of equal-classified NDVI, for 2 crop cycles, 2002-2003 and 2003-2004, and for one date in 2004. 


\section{Annual variations of NDVI patterns}

Around the peak of vegetation growth (images 1, 3, and 4 for 2002-2003 - image 2 was eliminated, cf. previous section - and images 11, 12, and 13 for 2003-2004 in Figure 3), the within-field NDVI patterns are comparable for both crop cycles, but the values of the classes are inverted (Figure 4;Table 2). This unexpected feature can be attributed to the interaction between topography and climate conditions. The analysis of the field topography (Figure 1) indicates that during the dry year (2002/03), the NDVI is maximal in the lower part of the field, while in the rainy year (2003/04), the NDVI is maximal in the higher part of the field. Similarly, during the wet year, the NDVI is minimal in the lower part of the field, while in the rainy year (2003/04), the NDVI is minimal in the higher part of the field. This observation is confirmed by the correlation values obtained between elevation and NDVI at pixel scale (Figure 2); negative values are obtained for the dry year, while positive values are found for the wet year. The best correlations are obtained with the images acquired around the peak of vegetation growth (between November and February), except for the two outliers (October 24, 2002 and April 12, 2004).

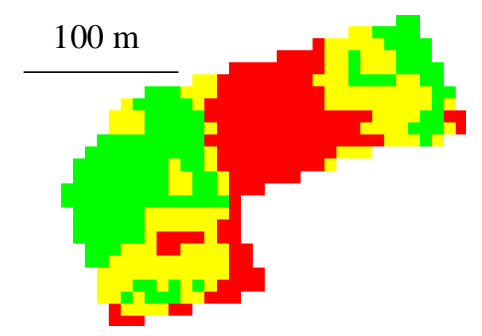

a) 2002-2003 growing season

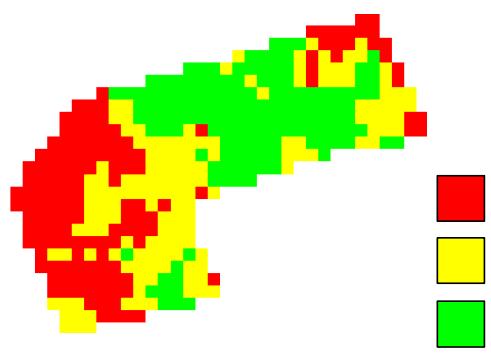

b) 2003-2004 growing season $1^{\text {st }}$ tercile (lower NDVI) $2^{\text {rd }}$ tercile $3^{\text {rd }}$ tercile (higher NDVI)

Figure 4 : Tercile representation of average NDVI images for the (a) 2002-03 and (b) 200304 vegetation peak periods. Images involved in the mean calculation were Sept. 19, Oct. 24, January 21 and February 11 for (a) and January 4, January 31 and March 1 for (b). 


\section{DISCUSSION}

At the seasonal scale, the within-field growth pattern depends on the phenological stage of the crop. During the early growth stages, the within-field spatial variability pattern is erratic and then stabilizes when the crop is fully developed and the soil is no longer visible. This result is in agreement with the studies of Zarco-Tejada et al. (2005) and Yang and Everitt (2002) which showed that the best correspondence between the spatial pattern of NDVI and yield were obtained with airborne images acquired around peak vegetative development, before the maturation stage when the plants are senescing. However, we showed in our data set that even images acquired around the vegetation peak could be outliers, showing unexpected spatial patterns. Our hypothesis is that specific climatic events could be strong enough to momentarily change the architecture of the crop.

At the annual scale, when averaging the NDVI maps around peak biomass, we found a stable pattern for both years, but with very different NDVI values. These potential yield variations can be directly linked to the topography and consequently to the water conditions of the plant, with limited water stress during the dry year in the lower part of the field and water logging during the rainy year. The influence of the topography was previously shown by Marques Da Silva and Alexandre (2005), who proposed topographical indices to help in sitespecific management for delineating areas where crop yields are more sensitive to extreme water conditions. Our results confirmed the observations obtained by yield monitoring; Eghball and Varvel (1997) and Lamb et al. (1997) showed that, under rainfed conditions, the temporal variability of yields was more dominant than spatial variability, indicating that spatial patterns in grain yields were greatly affected by yearly climatic conditions, particularly by year-to-year changes in seasonal water supply. Schepers et al. (2004) reached the same conclusions on irrigated corn crops and explained it by variations in soil properties affecting water-supplying capacity. 


\section{CONCLUSION}

From the literature, results from within-field variability studies do not always agree. This may be due to a lack of consistency of the results over a series of years, or because soil properties may not have explained the observed yield. To respond to the difficulties in the interpretation of the studies carried out, the use of high resolution satellite imagery or aerial photography time series could be one solution. In this paper, we showed through an example using satellite remote sensing, how the cropping and environmental factors impact the within-field temporal variability. Our results showed that (1) it is necessary to know the crop phenology in order to interpret correctly the spatial pattern, and that (2) single date images can be insufficient for the diagnosis of crop conditions or for predictions. We concluded that the pattern of crop vigour occurrence within fields could help to diagnose the causes of crop growth anomalies which can then be verified by ground inspection and sampling.

The results obtained in this paper highlight the potential of satellite remote sensing to support crop management decision-making. This contribution is mainly based on multi-temporal NDVI acquired at the field-scale. An increase in the availability of decametric/metric image time series can be expected soon with the launch of satellites with high revisit time such as Formosat or Venus, or with the growing use of light airborne systems. This contribution should be further improved when NDVI time series are combined with other data sources such as hyperspectral measurements, or when the NDVI times series are analysed with tools such as geostatistics to better characterize crop conditions, hasten crop diagnosis, and improve yield predictions. 


\section{ACKNOWLEDGEMENTS}

Most of the results presented here emanate from the SUCRETTE project funded by the French Ministry of Research (RTE Program). Thanks to Stéphanie Catsidonis for helping with data acquisition and to Dominique Tressens for giving access to Gardel fields and databases.

\section{REFERENCES}

Almeida, T.I.R., De Souza, C.R.,Rossetto, R., 2006. ASTER and Landsat ETM+ images applied to sugarcane yield forecast. International Journal of Remote Sensing, 27(19), 40574069 .

Anderson, G.L.,Yang, C., 1996. Multispectral videography and geographic information systems for site-specific farm management. In: Proceedings of 3rd International Conference on Precision Agriculture, edited by Robert, P., Rust, R. H. and Larson, W. E. (ASA, CSSA, SSSA, Madison, WI, USA), p. 681-692.

Boydell, B.,Mc Bratney, A.B., 2002. Identifying potential within-field management zones from cotton-yield estimates. Precision Agriculture, 3, 9-23.

Cabidoche, Y.M., 1985. Distribution des sols à argiles gonflantes sur calcaires récifaux (zone Caraïbe) - Utilisation de mesures de résistivité électrique (Distribution of expanding clay soils over reef limestone in the Caribbean - Use of electric resistivity). In : Proceedings of Séminaire scientifique de pédologie pour la région de l'Amérique Centrale et des Caraïbes, edited by ORSTOM (Paris, France), p. 187-221. 
Eghball, B.,Varvel, G.E., 1997. Fractal analysis of temporal yield variability of crop sequences: Implications for site-specific management. Agronomy Journal, 89(6), 851-855.

Hesse, A., 1966. Prospections géophysiques à faible profondeur. Applications à l'archéologie (Low depth geophysical prospecting - Application to archaeology), edited by Dunod, Paris, France, 149 pp.

Lamb, J.A., Dowdy, R.H., Anderson, J.L.,Rehm, G.W., 1997. Spatial and temporal stability of corn grain yields. Journal of Production Agriculture, 10(3), 410-414.

Lelong, C.C.D., Pinet, P.C.,Poilvé, H., 1998. Hyperspectral imaging and stress mapping in agriculture : a case study on wheat in Beauce (France). Remote Sensing of Environment, 66, 179-191.

Machado, S., Bynum, E.D., Archer, T.L., Lascano, R.J., Wilson, L.T., Bordovsky, J., Segarra, E., Bronson, K., Nesmith, D.M.,Xu, W., 2002. Spatial and temporal variability of corn growth and grain yield: Implications for site-specific farming. Crop Sciences, 42, 1564-1576. Marques Da Silva, J.R.,Alexandre, C., 2005. Spatial Variability of Irrigated Corn Yield in Relation to Field Topography and Soil Chemical Characteristics. Precision Agriculture, 6(5), 453-466.

Moran, M.S., Inoue, Y.,Barnes, E.M., 1997. Opportunities and limitations for image-based remote sensing in precision crop management. Remote Sensing of Environment, 61, 319346.

Pinter, P.J., Hatfield, J.L., Schepers, J.S., Barnes, E.M., Moran, M.S., Daughtry, C.S.T.,Upchurch, D.R., 2003. Remote Sensing for Crop Management. Photogrammetric Engineering \& Remote Sensing, 69(6), 647-664.

Ribbes, F., Bégué, A., Siegmund, B., Todoroff, P.,Autrey, L.J.C., 2002. Potentialités de la télédétection satellitaire pour la filière canne à sucre - Projet SUCRETTE (Potential of satel- 
lite remote sensing for the sugarcane industry - SUCRETTE project). In : Proceedings of Perspectives de développement de la canne à sucre en milieu insulaire : approches technico-économiques, sociales et culturelles, Réunion, France, 10 pp.

Rouse J. W., R. H. Hass, J. A. Schell and D. W. Deering, 1974. Monitoring vegetation systems in the Great Plains with ERTS, Technical Report (Accession Number: 74N30727;

Document ID: 19740022614), NASA Center, USA, p. 309-317.

Schepers, A.R., Shanahan, J.F., Liebig, M.A., Schepers, J.S., Johnson, S.H.,Luchiari, A., 2004. Appropriateness of management zones for characterizing spatial variability of soil properties and irrigated corn yields across years. Agronomy Journal, 96, 195-203.

Tucker, C.J., 1979. Red and photographic infrared linear combinations for monitoring vegetation. Remote Sensing of the Environment, 8, 127-150.

Yang, C.,Everitt, J.H., 2002. Relationships between yield monitor data and airborne multidate multispectral digital imagery for grain sorghum. Precision Agriculture, 3, 373-388.

Zarco-Tejada, P.J., Ustin, S.L.,Whiting, M.L., 2005. Temporal and spatial relationships between within-field yield variability in cotton and high-spatial hyperspectral remote sensing imagery. Agronomy Journal, 97(3), 641-653. 